This item was submitted to Loughborough's Research Repository by the author.

Items in Figshare are protected by copyright, with all rights reserved, unless otherwise indicated.

\title{
An integrated process and management tools for ranking multiple emerging threats to animal health
}

\section{PLEASE CITE THE PUBLISHED VERSION}

http://dx.doi.org/10.1016/j.prevetmed.2012.08.007

\section{PUBLISHER}

(c) Crown Copyright. Published by Elsevier Ltd

\section{VERSION}

AM (Accepted Manuscript)

\section{PUBLISHER STATEMENT}

This work is made available according to the conditions of the Creative Commons Attribution-NonCommercialNoDerivatives 4.0 International (CC BY-NC-ND 4.0) licence. Full details of this licence are available at: https://creativecommons.org/licenses/by-nc-nd/4.0/

\section{LICENCE}

CC BY-NC-ND 4.0

\section{REPOSITORY RECORD}

Del Rio Vilas, Victor J., Fay Voller, Gilberto Montibeller, L. Alberto Franco, Sumitra Sribhashyam, Eamon Watson, Matt Hartley, and Jane C. Gibbens. 2019. "An Integrated Process and Management Tools for Ranking Multiple Emerging Threats to Animal Health". figshare. https://hdl.handle.net/2134/25118. 


\title{
An integrated process and management tools for ranking multiple emerging threats to animal health
}

Victor J Del Rio Vilas, ${ }^{1,2}$, Fay Voller ${ }^{1,3}$, Gilberto Montibeller ${ }^{4}$, L. Alberto Franco $^{5}$, Sumitra Sribhashyam ${ }^{4}$, Eamon Watson ${ }^{3}$, Matt Hartley ${ }^{1,3}$, Jane C Gibbens $^{1,3}$.

${ }^{1}$ Department for Environment, Food and Rural Affairs. London, UK.

${ }^{2}$ Bechtel International Systems Inc, Tashkent, Uzbekistan.

${ }^{3}$ Animal Health Veterinary Laboratories Agency, London, UK.

${ }^{4}$ Department of Management, London School of Economics, London, UK.

${ }^{5}$ Warwick Business School, Warwick, UK.

*Corresponding author: vdelriovilas@yahoo.co.uk

\begin{abstract}
The UK's Department for Environment, Food and Rural Affairs supports the use of systematic tools for the prioritisation of known and well defined animal diseases to facilitate long and medium term planning of surveillance and disease control activities. The recognition that emerging events were not covered by the existing disease-specific approaches led to the establishment of the Veterinary Risk Group (VRG), constituted of government officials and supporting structures, the risk management cycle and the emerging threat highlight report (ETHiR), to facilitate the identification, reporting and assessment of emerging threats to UK's animal health. Since its inception in November 2009 to the end of February 2011, the VRG reviewed 111 threats and vulnerabilities (T\&V) reported through ETHiR. In July 2010 a decision support system based on multi-criteria-decision-analysis (MCDA) improved ETHiR to allow the systematic prioritisation of emerging T\&V. The DSS, known as e-THiR, allows the regular ranking of emerging T\&V by calculating a set of measurement indices related to the actual impact, possible impact on public perception, and level of available capabilities associated with every $T \& V$. The systematic characterisation of the processes leading to the assessment of $\mathrm{T} \& \mathrm{~V}$ by the VRG has led to a consistent, auditable and transparent approach to the identification and assessment of emerging risks. The use of MCDA to manage a portfolio of emerging risks represents a different and novel application of MCDA in a health related context. This paper describes and discusses the characterisation and management of emerging risks by the VRG since its inception, and results from a pilot application of the e-THiR system to a reduced set of emerging threats.
\end{abstract}

Keywords: emerging threats, vulnerabilities, prioritisation, multi-criteria-decisionanalysis.

\section{Introduction}

Since the financial crisis in 2009, organisations in many domains have recognised the increasing need to rationally allocate scarce resources to the management of emerging 
risk events (Anon. 2009a). The UK agricultural administrations are not an exception: early identification of new animal health threats is one of the cornerstones of the UK Veterinary Surveillance Strategy (VSS) (Defra 2003), translated into the development of a risk and impact-based prioritisation process. To this end, the UK Department for Environment Food and Rural Affairs (Defra) has developed and is now piloting a structured and systematic approach to the prioritisation of diseases, now known as the "Disease briefing, Decision support, Ranking and Risk assessment database" (D2R2) (Defra 2004). D2R2 allows the long and medium term allocation of resources towards, for example, surveillance and disease preparedness. It assesses known diseases and relies on a set of common criteria, such as the reasons for Government intervention (Defra 2004), and a comprehensive characterisation of the conditions and control measures (i.e. profiling) to produce a rank order of diseases. To date, over sixty diseases have been profiled and ranked. Elsewhere, similar exercises have been conducted for diseases of public health importance. For example, Krause et al. (2008) and subsequently Gilsdorf and Krause (2011) reported the application of a weighted multi-criteria approach to 85 pathogens of public health importance leading to pathogen-specific scores that allowed their ranking.

Whereas disease profiling and prioritisation is a valid exercise that allows systematic comparisons to support strategic resource allocation, it cannot capture all possible manifestations of the hazards given a specific setting and risk pathway. Additional steps to capture this heterogeneity would allow the regular update of the strategic prioritisation tool, D2R2 in our setting, and ensure comprehensiveness in its scope.

In 2009, to address the recommendations of Defra's Science Advisory Council and in response to the Anderson Review of the 2007 foot-and-mouth outbreak in England (Anon. 2008), the Veterinary Risk Group (VRG) was established to regularly monitor, rank and escalate for action emerging animal health related risks. The VRG, in effect, was formed to help Defra to avoid the four most common issues affecting organisations in their management of emerging risks (Anon. 2009a), namely: (i) the lack of alignment of risk management practices within the organisation's regular processes, (ii) the insufficient resource to interpret risk information, (iii) communication shortfalls within the organisation and, (iv) the scarcity of adequate and fit-for-purpose methods to measure risk. For the latter, the VRG chose multicriteria-decision-analysis (MCDA) (Keeney \& Raiffa, 1993; Belton and Stewart, 2002) techniques to facilitate the systematic comparison of threats leading to their prioritisation.

The use of MCDA in health settings is not new. Earlier works include the application of MCDA to the evaluation of health interventions and their rank ordering in multiple settings (e.g Baltussen and Niessen 2006, Felli et al. 2009, Mourits et al. 2010, Walshe and Burgman 2010). Hongoh et al. (2011) reviews the use of MCDA, together with geographic information systems, for the management of diseases, and shows a different application of MCDA, that of the geographical area based assessment for a given threat. By contrast, our work uses MCDA as a means to help prioritise resources and build up capabilities to manage a portfolio of emergent risks, rather than to choose a single best option or focus on a single event. To our knowledge this represents a different and novel application of MCDA in a health related context. 
This paper describes the structures and processes created for the comprehensive identification and advice on management of emerging animal related threats in the UK. Specifically, the paper describes and discusses the characterisation and management of emerging risks by the VRG since its inception in November 2009 and the pilot application of MCDA techniques to a reduced set of emerging threats from July 2010.

\section{Materials and methods}

\subsection{Risk identification process}

A common constraint in many organisations is a disconnected approach to the identification, evaluation and response to emerging events, without formal integration with other strategic decision-making processes (Anon. 2009a). Within Defra, the Risk Management Cycle (RMC), a suite of tools, structures and processes guarantees a systematic and integrated approach to the management of emerging risks.

As part of the RMC, the VRG manages emerging animal health related threats and vulnerabilities (T\&V) reported by a number of risk managers (RMs) within Government. These managers are officials responsible for risk portfolios. The following portfolios have reported regularly to the VRG since its inception: International Disease Monitoring, Import Risk, Animal Demographics, Early Warning Surveillance, Wildlife-Aquatic and Zoo Animal Issues, Zoonoses, and the Veterinary Exotic Notifiable Diseases Unit (VENDU). These are the main areas in which unexpected threats that require the development of policy may arise. This list is not comprehensive as other risk portfolios exist within Government, for example, those dealing with tuberculosis or transmissible spongiform encephalopathies. These two portfolios were not part of the initial pilot phase here reported, although later joined the group of risk portfolios reporting to VRG at the time of writing (Autumn 2011).

The definition and nature of the risk events to be reported to the VRG were discussed at length within the group and RMs. The consensus was that threats, defined as " $a$ risk resulting from a newly identified hazard to which a significant exposure may occur or from an unexpected new or increased significant exposure and/or susceptibility to a known hazard" (EFSA 2011), and vulnerabilities, defined as "the exposure to uninsured risk leading to a policy-based unacceptable level of animal health", would be reported to the VRG. The case definition was narrowed to include $\mathrm{T} \& \mathrm{~V}$ of technical nature only. That is, resource related issues, for example shortages in staff within the areas of responsibility of RMs, were excluded from submission to the VRG.

Every month RMs report all emerging $\mathrm{T} \& \mathrm{~V}$ within their risk portfolio, except those already identified in their portfolio plans, via the completion of an Excel ${ }^{\circledR}$-based template, named the Emerging Threat Highlight Report (ETHiR), collated by the VRG's secretariat. The information provided by the RM through ETHiR contains: (i) a brief description of the threat; (ii) a description of the risk pathway that reflects the RM's perception of the possible route and manifestation of the threat; (iii) the RM's interpretation of the threat's relevance against the reasons for government 
intervention; and, (iv) the risk mitigation measures proposed or put in place by the RM within his/her portfolio.

Once all the monthly T\&V are compiled through ETHiR, the VRG may then agree with the RMs assessments, make recommendations on mitigating actions, or request further information from the RM before submitting the VRG report of the month to the four CVOs' (Chief Veterinary Officers for England \& UK, Wales, Scotland and Northern Ireland) monthly meeting. The cycle is completed with recommendations by the CVOs, who may request further information, initiate policy development, advise on intervention, or closing the risk if CVOs consider that no further mitigation measures are needed.

Against the above background, a decision support system (DSS), informed by ETHiR, was introduced in July 2010. The DSS, an interactive Excel ${ }^{\circledR-}$ based tool that became known as e-THiR, was specifically developed to support the evaluation and prioritisation of emerging animal related T\&V within Defra.

\subsection{Development of the e-THiR system}

The e-THiR system was developed using a facilitated modelling approach (Franco and Montibeller, 2010), and required involvement of experts from Defra and the Veterinary Laboratories Agency (VLA). Adoption of this approach to modelling was based on evidence that the involvement of stakeholders in the development of decision support systems increases the chance that it will be employed in practice (Kaplan et al 2001). The core element of the system is a decision model informed by multi attribute utility theory (Keeney and Raiffa, 1993), and amenable to multicriteria decision analysis (MCDA). The model comprised three sub-models: the public perception model, the impacts model and the capabilities model (see below).

Model development followed common steps for each of the three sub-models, namely: (i) defining evaluation criteria; (ii) eliciting impact functions that allow the quantitative scoring of threats; (iii) defining criteria weights; and, (iv) model testing 1. The adoption of a facilitated modelling approach allowed Defra and VLA experts to contribute to model parameter definition and testing throughout the model development process. In the next section, we describe in some detail the development of the public perception model (for an accessible description of the methodology see Montibeller and Franco 2007). For the other two models, we limit our description to specific characteristics.

\subsection{Public perception model}

The development of evaluation criteria for the public perception model drew on existing research into strategic risk assessment of environmental risks (Anon 2009b). A group causal mapping (Bryson et al., 2004) session was conducted where the VRG agreed on three key evaluation criteria associated with an expert assessment of public perception: personal concern, public concern, and discontent. Personal concern was defined as "the degree of potential personal concerns about a threat, in terms of the health, economic or social consequences that it may cause”. Public concern was defined as "the degree of potential public concern about a threat, in terms of animal suffering and affective connection to the species". Finally discontent was defined as 
"the degree of potential public discontent about the expected management of a threat and the level of constraint that risk management measures can impose”. The mapping session, followed by workshops with Defra's experts, also led to the definition of levels (descriptions of possible consequences) of increasing impact within each criterion.

An impact function, associated with such levels, was elicited from the Defra's experts using the Macbeth approach (Bana e Costa 2005). Each impact function represents the relative decrease in impact for each lower level of $\mathrm{T} \& \mathrm{~V}$ and is anchored at 100 (highest impact) and 0 (lowest impact) (see Table 1). It is worth noting that the marginal impact between adjacent levels is not necessarily the same, reflecting the non-linear nature of such impact functions. This is counter to the oft taken linearity assumption made in animal health risk assessments, which is inadequate as highlighted by Del Rio Vilas et al. (2011).

The final preference parameters elicited for this model were the criteria weights, which represent value trade-offs. Such weights should be elicited by considering the relative importance of the ranges of each attribute used to operationalise the criteria (from its highest to the lowest impact), avoiding the common mistake that weights would represent 'direct importance' (Keeney, 2002). One of the psychometrically correct, and simplest, elicitation protocols is the swing-weights approach, where decision makers are asked to consider the 'swing' of reducing the impact from the highest to the lowest impact level on each attribute, and then to assess the relative value of each of those swing reductions (von Winterfeldt and Edwards, 1986). Weights were elicited with members of the VRG during a separate dedicated meeting by using such approach. The resulting weights, after normalisation, were: $43 \%$ for personal concern, $22 \%$ for public concern and 35\% for discontent. These weights in effect represent conversion rates of each partial evaluation into the overall Public Perception criterion, and were used during the pilot period described here.

\subsection{Impacts model}

Emerging $\mathrm{T} \& \mathrm{~V}$ were assessed against their impact on the four reasons for government intervention defined in Great Britain Animal Health and Welfare Strategy (Defra 2004), namely, "public health", "animal welfare”, "wider economy, environment and society" and "international trade". As in the public perception model, we defined impact functions for each of the four reasons for government intervention. Figure 1 shows the impact function for the public health criterion with two attributes: "severity of symptoms" on the vertical axis, and "degree of exposure" on the horizontal axis. Figure 1 also shows examples of threats for each of the possible combinations of the two attributes. These examples were provided by VRG and VLA experts to facilitate the assessment of new $\mathrm{T} \& \mathrm{~V}$ by the RMs. We note that it is possible for multiple combinations of the levels within the attributes to have the same scores, as for levels 4 and 5 with a score of 75 . This is so because different combinations of clinical signs and degree of exposure may produce the same overall quantitative impact, as the two dimensions are not preferentially independent.

As for the public perception model, the swing weighting approach was employed for eliciting the weights for the four reasons for government intervention. The normalised 
weights were: $43 \%$ for the public health criterion, $17 \%$ for animal welfare, $32 \%$ for the wider society criterion and $9 \%$ for international trade. However, pending validation with policy makers, the four reasons for government intervention are all equally weighted at present, at $25 \%$.

\subsection{Capabilities model}

The capabilities model was developed with the assistance of Defra and VLA experts at two meetings. This model aimed to assess the response to the emerging $T \& V$. Three criteria were selected: evidence assessment, defined as the amount of evidence available about the $\mathrm{T} \& \mathrm{~V}$ and how accessible it is for policy making; resources, defined as the amount of overall resources available (e.g. infrastructure, skills, financial resources, for tackling the $\mathrm{T} \& \mathrm{~V})$; and, counter-measures, defined as legislative powers, control strategies, contingency plans and disease control and surveillance tools in place to deal with a $\mathrm{T} \& \mathrm{~V}$. After the elicitation of the impact functions, a 0-100 scale was built within each criterion and reference levels were defined to quantify the availability of each capability. Finally, as for the previous models, weights were elicited using the swing approach. The allocated normalised weights were: $31 \%$ to the evidence assessment criterion, $38 \%$ to the resource criterion, and $31 \%$ to the counter-measures criterion.

\subsection{Implementation of the tool}

Each of the three evaluation models (to assess impact, public perception, and capability) had sub-criteria designed in such a way that they were preferentially independent. For this reason, a simple linear additive function (Keeney and Raiffa, 1993) could be employed to aggregate partial impact scores of a given $T \& V$, from each sub-criteria of the model. Every $T \& V$ is therefore assessed by these three evaluation models, each model providing an overall score. The three models above were implemented as a user friendly Excel ${ }^{\circledR}$-based DSS tool programmed in Visual Basic. The DSS tool is available upon request from the first author. The tool allows easy and direct scoring of the T\&V by the RMs by clicking on interactive screenshots such as the one shown in Figure 1. For each T\&V the system is able to calculate: (i) an overall potential impact index scaled from 0 , the lowest impact, to 100 , the greatest impact; (ii) an overall (expert assessed) public perception index scaled from 0, the lowest, to 100, the greatest; (iii) an overall capability index scaled from 0 , the lowest capability, to 100 , the greatest capability; (iv) the ratio overall potential impact to overall capability, which draws attention to threats with relative high impact and low capability built; and, (iv) the ratio overall public perception to overall impact, which draws attention to discrepancies between the actual impact of a threat and how the public may perceive it.

$\mathrm{T} \& \mathrm{~V}$ can be prioritised according to any of the three indices or two ratios above. The VRG focuses primarily on those T\&V with higher ratios values. For the ratio overall impact to overall capability, a higher value may suggest the need for management actions in terms of impact reduction, capability building or both. For the ratio overall public perception to overall impact, a higher value may suggest management actions in terms of education or information to the public.

\subsection{Descriptive assessment of $T \& V$}


The pool of all T\&V reported to the VRG in the period of study, November 2009 to February 2011, were first classified as incident or recurrent depending on whether they were raised previously or not at any time. Further, incident $T \& V$ were then classified by the authors (Table 2) following earlier classifications in the literature (Jones et al. 2008). Mitigating actions suggested by the RMs, the VRG and the four CVOs for all the T\&V could also be grouped in three classes that indicate the degree of evidence available to inform decisions: i) monitoring the situation, ii) requesting further evidence, and iii) policy development. Given the Government commitment to prompt and regular communication with stakeholders, we also report the instances in which this measure was recommended.

\section{Results}

\subsection{Descriptive analysis}

A total of $111 \mathrm{~T} \& \mathrm{~V}$, an average of eight per month, were reported to the VRG in the period of study. This number includes items reported more than once to the system. Seventy-four unique or incident $T \& V$ were reported during the period of study at an average of five per month. The number of all reported T\&V $(n=111)$ showed no significant trends in time nor any of the classes within (prevalent and incident).

Of the 74 incident T\&V, 43 (58\%) were threats and 31 (42\%) vulnerabilities. Within the latter, 7 (22\%) were related to constrained resources, 8 (26\%) to lack of evidence and $16(52 \%)$ to others.

The classification of threats according to their potential drivers returned 10 (24\%) threats possibly linked to socio-economic factors (mostly related with importation and trade of animals and/or their produce, e.g. "Equine infectious anaemia diagnosed in the UK and Belgium in imported horses") and 15 (36.6\%) possibly linked to ecological/environmental factors (e.g. "Increased risk of wild birds coming into contact with poultry and transmitting a notifiable disease as the cold weather affects roost sites"). The remaining threats (18) could have been triggered by either class or a combination of both drivers. Half of the threats were classified as truly emerging as per our definition (Table 2) whereas increased awareness by the RMs explained the other half.

The geographical distribution of the threats according to their reported origin was as follows: 21 originated in Great Britain, 13 originated in continental Europe (includes Israel and Russia), 3 in North America and 1 in Asia. Five threats to Great Britain had a vague or global origin. All 31 vulnerabilities affected national structures or processes.

Forty-five (61\%) of the incident T\&V could be linked to domestic species, 5 (7\%) to wildlife species and 24 (32\%) to both domestic and wildlife species. Vulnerabilities did not appear as species-specific as threats with 18 (58\%) of the 31 vulnerabilities not linked to any species in particular. By species, the distribution of the $\mathrm{T} \& \mathrm{~V}$ was as follows: $15 \%$ were swine specific, $12 \%$ equidae specific, $11 \%$ cattle specific, $12 \%$ related to other ruminants, $11 \%$ to birds, $8 \%$ to others (e.g. wildlife and pets), and $5 \%$ to fish and shellfish. Over one quarter of all the incident $T \& V$, mostly vulnerabilities, 
were generic or not species-specific (e.g. "Threats and vulnerabilities may not be appropriately prioritised within Defra”).

In terms of the classification by pathogen, threats could be classified as follows: 24 caused by viruses (56\%), 8 by bacteria (19\%), 3 by protozoa $(7 \%), 3$ by other parasites (7\%), 2 by rickettsia (5\%), 2 were related to antimicrobial resistance or anthelmintic resistance events (5\%) and 1 was caused by prions (2\%). Only three vulnerabilities were pathogen specific (one linked to bacterial and two linked to viruses). Of the $46 \mathrm{~T} \& \mathrm{~V}$ that could be linked to pathogens, twelve (26\%) were related to vector-borne agents and 18 (39\%) were zoonotic.

Table 3 shows the classification of mitigating actions against $85 \mathrm{~T} \& \mathrm{~V}$ for which records exist. Note that this classification was done for all $\mathrm{T} \& \mathrm{~V}$, incident and prevalent. Specific "policy development" was recommended for $16 \mathrm{~T} \& \mathrm{~V}$ (19\%) of which changes in sampling or testing regimes were the most frequent $(n=6)$.

\subsection{Outputs from e-THiR.}

Up to February 2010 twenty two T\&V were prioritised with the new e-THiR tool. We present a selection of three $T \& V$ that shows the operation of the new tool (Figure 2) and describe the tool's full output for one T\&V: a recent investigation by the VLA of an outbreak of Salmonella Dublin with parasitic gastroenteritis with relative high mortality in captive reindeer. The reader will be able to interpret the outputs for the other two T\&V, namely: i) a $\mathrm{Q}$ fever related abortion storm in a goat farm in north east England, and ii) the potential increased prevalence of Salmonella 4,5,12:i:-.

The outbreak of Salmonella Dublin with parasitic gastroenteritis in captive reindeer scored 65 on Public Health impact as the RM considered that exposure by the public to the hazard was "low" and the severity of symptoms on people "serious". The welfare implications of this threat were deemed moderate with a score of 65. With regard to the threat's impact on wider society, the RM deemed that the threat's impact would be restricted to the local environment and with affectation of mainly primary producers. Finally, the RM assessed that this threat would not lead to an export ban and hence the score was 0 against international trade. Specifically on this criterion, and for comparison purposes only, the threat of Aujeszky's disease in France in 2010 scored 80 given the range and value of the commodities affected and the duration and geographical spread of the hazard if it happened in Great Britain. The overall impact given to the death of captive reindeer was 36 .

The assessment of capabilities by the RM shows that evidence was deemed relatively strong and ready for immediate use, the resources were sufficient and the countermeasures limited. The RM deemed that, overall capabilities were adequate with a score of 81.

According to the expert assessment of public perception, the occurrence of death in captive reindeer scored 48 . In more detail, the RM considered that i) the threat would be perceived as moderate by the public (score of 25), ii) it would lead to some suffering in species dear to the public and create high media interest (score of 90), and 
iii) the public would not mistrust the way the Government would manage the threat although there might be some constraints on some sectors of the reindeer population.

The deemed relatively low impact score and sufficient capabilities led to an "Impact/Capability ratio" of 0.45 . In other words, according to the RM, and at the time of the assessment, capabilities were deemed more than sufficient to address the threat. Similarly, the RM's assessment led to a ratio "Public perception/impact" $>1$. The RM considered that the public would perceive this threat with greater concern than its impact would objectively merit.

\section{Discussion}

4.1. User evaluation.

Even in its simplest form, that is, restricted to a purely qualitative characterisation of emerging threats, the systematic management of emerging risks delivers a number of benefits to any organisation. Specific to our setting were: i) the ability to rapidly assess a very large number of emergent risks with limited available information, ii) a systematic, accountable and auditable means to process diverse risk information, prioritise risks and identify possible risk management options, and iii) increased efficiency thanks to a holistic and integrated approach to threat assessment that facilitated functional and communication channels across the vertical-structured risk streams within government. Indeed, a survey to 350 senior executives of global organisations identified "the integration and effective interpretation of risk information in terms of impact on their business processes and organisations' strategy" as the greatest challenge in assessing risks (Anon. 2009a). At a tolerable cost of 0.3 man-years, the RMC also supports a number of desirable and exchangeable competences, e.g. making effective decisions that deliver benefits across the entire organisation.

Specifically on the e-THiR system, the tool has provided a systematic framework to hold discussions within the VRG and between the VRG, RMs and the four CVOs. The VRG has used the outputs from the e-THiR system to i) validate RMs' assessments and suggested mitigating actions, ii) identify the reasons for government intervention on which the impact will be greatest, iii) provide a consistent benchmark, i.e. ratios, against which the VRG assess the relative severity of threats, and, iv) identify the levels of risk mitigation needed.

We note that, due to the reduced number of $T \& V$ considered at each meeting during the pilot period, the specific descriptions provided by the RMs coupled with the expertise of the VRG members had a greater influence on the management of the threat than the scores provided by the e-THiR system. This approach to the judgment of preferences, defined as holistic in behavioural decision making, is common in many settings (Arkes et al., 2010). A larger number of $\mathrm{T} \& \mathrm{~V}$ might warrant disaggregated assessments whereby each alternative is rated against each of several criteria by the VRG, given the strong evidence that disaggregated assessments are more precise than holistic ones (Arkes et al., 2010). In effect, using the e-THiR system to its full potential.

\subsection{Development and operation of the system}


Throughout the development of the system, a balance had to be found between comprehensiveness and simplicity. We allocated greater weight to the latter, see Edwards et al. (1988) for a discussion on the subject, pressed by the need to deliver flexible approaches that could be used within a reasonable time scale and would allow the incorporation of extensions in the future. Indeed, in our experience, the main difficulty comes not from the technical challenges of the approach but from its implementation. Simplicity was actively pursued to increase the acceptability of the tool within the organisation, and in particular, within the group of users, the RMs.

RMs are requested to report all the $T \& V$ identified during the reporting month. Some of them are not risk stream specific and could lead to a situation where the same T\&V is reported and scored by more than one risk stream. This event, that reflects the overlapping recognition of $\mathrm{T} \& \mathrm{~V}$ by the risk sources, occurred on a number of occasions before the implementation of the e-THiR system. The VRG response was to consider the multiple reporting of a threat as an indicator of the threat's potential for wider impact, on a number of portfolios. The current architecture of the e-THiR system would not stop the multiple reporting of a threat, as they may impact different portfolios and have distinctive risk paths. The system has yet to develop ways to account for the multiplicity of impacts that can lead to different scores for the same $\mathrm{T} \& \mathrm{~V}$. RMs are also requested to describe the risk pathway for every $T \& V$. This requirement was not originally in place, before e-THiR had been developed, and led to the reporting of a number of issues for which no clear risk pathway to UK's interests could be defined. This has reduced the possibility of recency bias, or the tendency to focus on recent events, occurring.

We also favoured flexibility, so the criteria embedded in the e-THiR system would allow the prioritisation of a very heterogeneous pool of T\&V. This flexibility stems from two severe simplifications of our assessment, regarding the probability of occurrence of a given threat and its imminence. Basically, these two key parameters are not considered in our models, as we implicitly assumed that all $\mathrm{T} \& \mathrm{~V}$ have the same probability of occurrence and are equally imminent. Thus we merely assess the impact of the threat, given a defined risk pathway, once the threat occurs in Great Britain. Extensions to incorporate and weigh adequately these two parameters could be of benefit in future developments of the decision support tool.

The facilitated workshops led by MCDA experts in the development phase of the tool were fundamental in avoiding common methodological mistakes (Del Rio Vilas et al., 2011). At these meetings, participants faced psychological and social negotiation problems similar to those described during regular strategic workshops (Montibeller and Franco 2011). Specifically, expert facilitation was critical in the construction of the public perception and capabilities model through the use of causal maps and the elicitation of the key elements related to the decision framework.

\subsection{Data issues}

Evidence on emerging risks is frequently scarce, of poor quality and has limited availability. In such situations, and to inform the decisions relating to the management of risks, any evidence-based decision should consider facts, which help to estimate impacts (e.g., potential number of cases of a given disease) and societal or organization values, which help to indicate how much the public or the organization 
cares about impacts (e.g., how serious are 10 cases versus 1000 cases of a given disease) (Anand 2002). The decision process should also consider trade-offs between multiple impacts which will indicate, for example, whether the public care more about the number of cases or the impact on the economy. Ideally we would like to have quantitative data informing these parameters, but for emerging threats we may have to content ourselves with (careful) expert assessment. Our approach to the public's perception and generation of risk indicators was a convenient one, based on RM's expertise and understanding of the problem. Informing our models with externally generated indicators of public perception could deliver additional benefits in the form of a socially fairer distribution of resources. Public perception can capture underlying social implications or inequalities not contemplated by objective assessments focused on rational choices and the delivery of the greatest return on the investment. Following Alan William's "fair innings argument" (Oliver 2009) whereby social preference may lead to compensate unfairness in the long term distribution of resources, a real public perception input could allocate greater priority to some species, stakeholders or subpopulations traditionally underrepresented in the list of beneficiaries from Defra interventions.

Extensions to this work are possible on several fronts, for example, on the handling of epistemic or systematic uncertainty. To this end, Bayes nets provide a framework for the quantification of uncertainty (Walshe and Burgman, 2010) although data and resource requirements appear quite considerable and may not be sustainable in the long term. Other extensions such as the adaptation to a scenario of multiple threats of Cooke's methodology (Cooke 1991), which allows a weighted pooled estimate of evidence from a heterogeneous group of calibrated experts, may merit study.

\subsection{Limitations}

Over the period reported here a reduced number of RMs contributed to the VRG. The motivation for this constraint was two-fold: i) to pilot a new concept on a small group of RMs and ii) to get their support to act as champions before new risk streams were added. The limited collection of T\&V that resulted from such small pool of risk streams can be criticised as not exhaustive and may result in a biased distribution of the observed $\mathrm{T} \& \mathrm{~V}$. For example, all 31 vulnerabilities described limitations affecting national systems. It is noticeable that RM did not report supra-national vulnerabilities, particularly of an EU origin, given the increasing influence of international rules and regulations on UK's disease surveillance and disease control measures.

The occurrence of artefacts affecting ascertainment of species is also likely. For example, the large contribution of $\mathrm{T} \& \mathrm{~V}$ affecting equidae (12\%) could indicate the presence of recall bias towards recent events like the outbreak of equine infectious anaemia in February 2010 in Great Britain (Defra 2010) that might have highlighted existing limitations concerning equidae registration and movements' controls. Simple weighing of species reports by the size of their national populations could add evidence to the presence of these biases. Bias-adjusted reporting rates were not part of the scope of the project and were not calculated. Similarly, the assessment of capabilities may also suffer from biases by means of its limited government-specific scope that may fail to capture the status of evidence available to other stakeholders. 


\section{Conclusions}

A recent history of high impact disease outbreaks in the UK and the identification that generic strategies based on known and well characterized diseases cannot adequately manage emerging threats, led to the development of the structures, processes and tools described here. Animal Health departments elsewhere are likely to face similar challenges to those confronted by the UK Government. In such situations, the integration of risk analysis in organisational practices, together with tailor-made decision tools, using well-established decision analytic principles, may be employed for the systematic management of emerging threats and vulnerabilities.

Even as a pilot project, the Risk Management Cycle has brought a number of benefits. The ability to compile and report the threats \& vulnerabilities shown here is the most immediate. On this ability, the e-THiR decision support system facilitated the quantification of impact, risk mitigation measures, and the expert assessment of public opinion that will support future comparisons of the Government's approach to emerging threats.

\section{Acknowledgments}

This research was partially supported by the contract grant VLA/Defra PU/V/WL/09/39.

\section{$\underline{\text { References }}$}

Anand, P., 2002. Decision-making when science is ambiguous. Science 295, 1839.

Anon., 2008. Foot and mouth disease 2007: a review and lessons learned. Crown copyright. Available here: http://archive.cabinetoffice.gov.uk/fmdreview/documents/fmd_2007_review_f ull.pdf. Accessed November 2011.

Anon., 2009a. Emerging Risks: Strategic Decision-Making in the Face of Uncertainty. Oliver Wyman. Available here: http://www.palisade.com/downloads/pdf/FT_Oliver_Wyman_whitepaper.pdf. Accessed November 2011.

Anon., 2009b. Annual Report. Defra Risk Project. The Collaborative Centre of Excellence in Understanding and Managing Natural and Environmental Risks. Cranfield University. Available here: http://www.cranfield.ac.uk/sas/risk/riskcentreannualreport2009.pdf. Accessed November 2011.

Arkes, H.R., Gonzalez-Vallejo, C., Bonham, A.J., Kung, Y-H., Bailey, N., 2010. Assessing the merits and faults of holistic and disaggregated judgments. Journal of Behavioral Decision Making 23, 3, 250-270.

Baltussen R., Niessen L., 2006. Priority setting of health interventions: the need for multi-criteria decision analysis. Cost effectiveness and Resource Allocation 4:14.

Bana e Costa, C.A., Corte, J.M., Vansnick, J.C., 2004. On the Mathematical Foundation of MACBETH. In: Figueira, J., Greco, S., Ehrogott, M. Multiple 
Criteria Decision Analysis: State of the Art Surveys, vol. 78 (New York: Springer-Verlag, n.d.), 409-437.

Belton, V., Stewart, T., 2002. Multiple criteria decision analysis: an integrated approach. New York: Springer.

Bryson, J.M., Ackermann, F., Eden, C., Finn, C., 2004. Visible Thinking: unlocking causal mapping for practical business results. Chichester: Wiley.

Cooke, R., 1991. Experts in uncertainty. Oxford University Press.

Defra 2003. Veterinary Surveillance Strategy. Available here: http://archive.defra.gov.uk/foodfarm/farmanimal/diseases/vetsurveillance/strat egy/documents/strategydoc.pdf. Accessed November 2011.

Defra 2004. Animal Health and Welfare Strategy. Available here: http://archive.defra.gov.uk/foodfarm/policy/animalhealth/index.htm. Accessed November 2011.

Defra 2004. Veterinary Surveillance: Disease Prioritisation. Available here: http://archive.defra.gov.uk/foodfarm/farmanimal/diseases/vetsurveillance/strat egy/programme/prioritisation.htm. Accessed November 2011.

Defra 2010. Equine Infectious Anaemia in Wiltshire. Epidemiology Report, situation at 4th February 2010. Nobel House, Smith Square, London, SW1P 3JR, UK. Version 1, Published 15th February 2010.

Del Rio Vilas, V.J., Montibeller, G., Franco, A., 2011. Letter to the editor: Prioritisation of infectious diseases in public health: feedback on the prioritisation methodology. Euro Surveillance 16, 27.

Edwards, W., von Winterfeldt, D., Moody, D.L. 1988. Simplicity in decision analysis: An example and a discussion. In: Bell, D.E., Raiffa, H., Tversky, A. (Eds.) Decision making: Descriptive, normative, and prescriptive interactions. New York, NY, US: Cambridge University Press, pp. 443-464.

EFSA (2011) Summary report EFSA Scientific Colloquium on emerging risks in food: from identification to communication, Parma, Italy.

Felli, J.C., Noel, R.A., Cavazzoni, P.A., 2009. A multiattribute model for evaluating the benefit-risk profiles of treatment alternatives. Med. Dec. Mak. 29, 1, 104115.

Foster, A., 2010. Common conditions of reindeer. In practice 32, 462-467.

Franco, L.A., Montibeller, G., 2010. Facilitated modelling in Operational Research. European Journal of Operational Research 205, 3, 489-500.

Gilsdorf, A., Krause, G., 2011. Prioritisation of infectious diseases in public health: feedback on the prioritisation methodology, 15 July 2008 to 15 January 2009. Euro Surveillance 16, 18.

Hongoh V., Gatewood Hoen A., Aenishaenslin C., Waaub J-P., Belanger D., Michel P., 2011. Spatially explicit multi-criteria decision analysis for managing vector-borne diseases. International Journal of Health Geographics 10:70.

Jones, K.E., Patel, N.G., Levy, M.A., Storeygard, A., Balk, D., Gittleman, J.L., Daszak, P., 2008. Global trends in emerging infectious diseases. Nature 451, 990-993.

Kaplan, S.E., Reneau, J.H., Whitecotton, S., 2001. The effects of predictive ability information, locus of control, and decision maker involvement on decision aid reliance, Journal of Behavioral Decision Making 14, 1, 35-50. 
Keeney, R.L, Raiffa, H., 1993. Decisions with multiple objectives: preferences and value trade offs. Cambridge University Press: Cambridge, $2^{\text {nd }}$ Edition.

Keeney, R.L., 2002. Common Mistakes in Making Value Trade-Offs. Operations Research, 50, 6, 935-945.

Krause, G., 2008. Prioritisation of infectious diseases in public health - call for comments. Euro Surveillance 13, 40.

Montibeller, G., Franco, L.A., 2007. Decision and risk analysis for the evaluation of strategic options. In "Supporting strategy: frameworks, methods and models". Chichester: John Wiley \& Sons Ltd.

Montibeller, G., Franco, L.A. 2011. Raising the bar: strategic multi-criteria decision analysis. Journal of the Operational Research Society, 62, 5, 855-867.

Mourits, M.C.M., van Asseldonk, M.A.P.M., Huirne, R.B.M., 2010. Multi Criteria Decision Making to evaluate control strategies of contagious animal diseases. Prev. Vet. Med. 96, 3-4, 201-210.

Oliver, A., 2009. A fair test of the fair innings. Med. Dec. Mak. 29, 4, 491-499.

Von Winterfeldt, D., Edwards, W., 1986. Decision analysis and behavioral research, Cambridge University Press Cambridge.

von Winterfeldt D., Edwards W., 1986. Decision analysis and behavioral research. New York: Cambridge University Press.

Walshe, T., Burgman, M., 2010. A framework for assessing and managing risks posed by emerging diseases. Risk Analysis, 30, 236-249.

\begin{tabular}{|c|c|c|}
\hline Criteria & Levels & Scores \\
\hline \multirow{5}{*}{ Personal concern } & Perceived threat: dreadful. Recent alarming/frightening news in the media (e.g. the BSE outbreak) & 100 \\
\hline & Perceived threat: serious. Recent alarming/frightening news in the media (e.g. the Avian Influenza outbreak) & 85 \\
\hline & Perceived threat: moderate. Recent adverse news in the media (e.g. the VTEC 0157 outbreak) & 50 \\
\hline & Perceived threat: moderate. No news in the media (e.g. the Q-fever in the Netherlands outbreak) & 25 \\
\hline & No perceived threat. No media reports (e.g. equine infectious anaemia 2010 outbreak) & 0 \\
\hline \multirow{5}{*}{ Public concern } & Severe suffering in species dear to the public. High potential media interest (e.g. rabies in puppies) & 100 \\
\hline & Some suffering in species dear to the public. High potential media interest (e.g. killing of badgers to control TB) & 90 \\
\hline & Some suffering in species the public is less concerned with high potential media interest (e.g. as BTV8 in cattle) & 65 \\
\hline & $\begin{array}{l}\text { Some suffering in species the public is not concerned with high potential media interest (e.g. Newcastle } \\
\text { Disease in poultry) }\end{array}$ & 35 \\
\hline & $\begin{array}{l}\text { No suffering in species the public is not concerned with low media interest (e.g. infectious salmon anaemia in } \\
\text { salmon) }\end{array}$ & 0 \\
\hline \multirow{5}{*}{ Discontent } & $\begin{array}{l}\text { Severe constraints on a large proportion of the population. Serious mistrust on the way it will be handled (e.g. } \\
\text { FMD } 2001 \text { outbreak) }\end{array}$ & 100 \\
\hline & $\begin{array}{l}\text { Some constraints on a large proportion of the population. Some mistrust on the way it will be handled (e.g. } \\
\text { Avian Influenza outbreak threat 2006) }\end{array}$ & 75 \\
\hline & $\begin{array}{l}\text { Some constraints on some sectors of the population. Some mistrust on the way it will be handled (e.g. } \\
\text { Newcastle Disease in pheasants) }\end{array}$ & 50 \\
\hline & $\begin{array}{l}\text { Some constraints on some sectors of the population. No mistrust on the way it will be handled (e.g. VTEC } 0157 \\
\text { outbreaks on open farms) }\end{array}$ & 25 \\
\hline & $\begin{array}{l}\text { Not likely to impose any constraints, It will affect only a minor proportion of the population. No mistrust on } \\
\text { the way it will be handled (e.g. equine infectious anaemia } 2010 \text { outbreak) }\end{array}$ & 0 \\
\hline
\end{tabular}


Del Rio, V., Voller, F., Montibeller, G., Franco, L. A., Sribhashyam, S., Watson, E., Hartley, M., \& Gibbens, J. 2013. An integrated process and management tools for ranking multiple emerging threats to animal health.

Preventive Veterinary Medicine, 108(2-3): 94-102. doi:10.1016/j.prevetmed.2012.08.007

Table 2

List of variables for the classification of threats and vulnerabilities (T\&V).

\begin{tabular}{ll}
\hline Variable & Categories \\
\hline Portfolio stream within Defra that contributes T\&V to ETHiR & (1) International Disease Monitoring. (2) Import Risk, (3) Animal Demographics, (4) \\
& Early Warning Surveillance, (5) Wildlife-Aquatic and Zoo Animal Issues, (6) Zoonoses, \\
& (7) VENDU \\
Whether entries are threats or vulnerabilities & (1) Threat, (2) Vulnerability \\
Type of vulnerability & (1) Lack/limited resources (e.g. training, skills, money), (2) Limitations in surveillance \\
& processes, organisational processes, regulatory framework, diagnostic tests, sampling \\
& regimes, (3) Lack/limited evidence \\
Type of species affected by the T\&V & (1) Domestic, (2) Wildlife, (3) Both \\
Hypothesized "driver/cause" that triggered the T\&V & (1) Socio-economic, (2) Environmental-ecological, (3) \\
Aetiology of T\&V & Political-regulatory-organisational \\
& (1) Bacteria, (2) Virus, (3) Rickettsia, (4) Prion, (5) Protozoa, (6) Others (e.g. fungi, \\
Emerging & helminths), (7) Antimicrobial resistance, (8) Anthelmintic resistance, (9) Unknown \\
& (1) Emerging, i.e. a completely new event regardless of its origin or a non-new discrete \\
Zoonosis & event/issue (elsewhere) but exotic to GB, (2) Non emerging \\
Vector borne & Yes/no \\
Species affected & Yes/no \\
Country where the T\&V originated & - \\
\hline
\end{tabular}


Figure 1. Impact functions for the impact of a given threat and vulnerability (T\&V) on the Public Health criterion. Vertical axis shows the severity of symptoms on people. The horizontal axis shows the degree of exposure of people to the hazard. The combination of these two attributes returns ten possible scenarios shown by the blue circles with white numbers (1 to 10). Impact functions for every scenario are shown in red. For every impact function there is an example of a hazard, fully described within the tool in terms of its context (not shown here) to help risk managers in the classification of emerging $T \& V$.
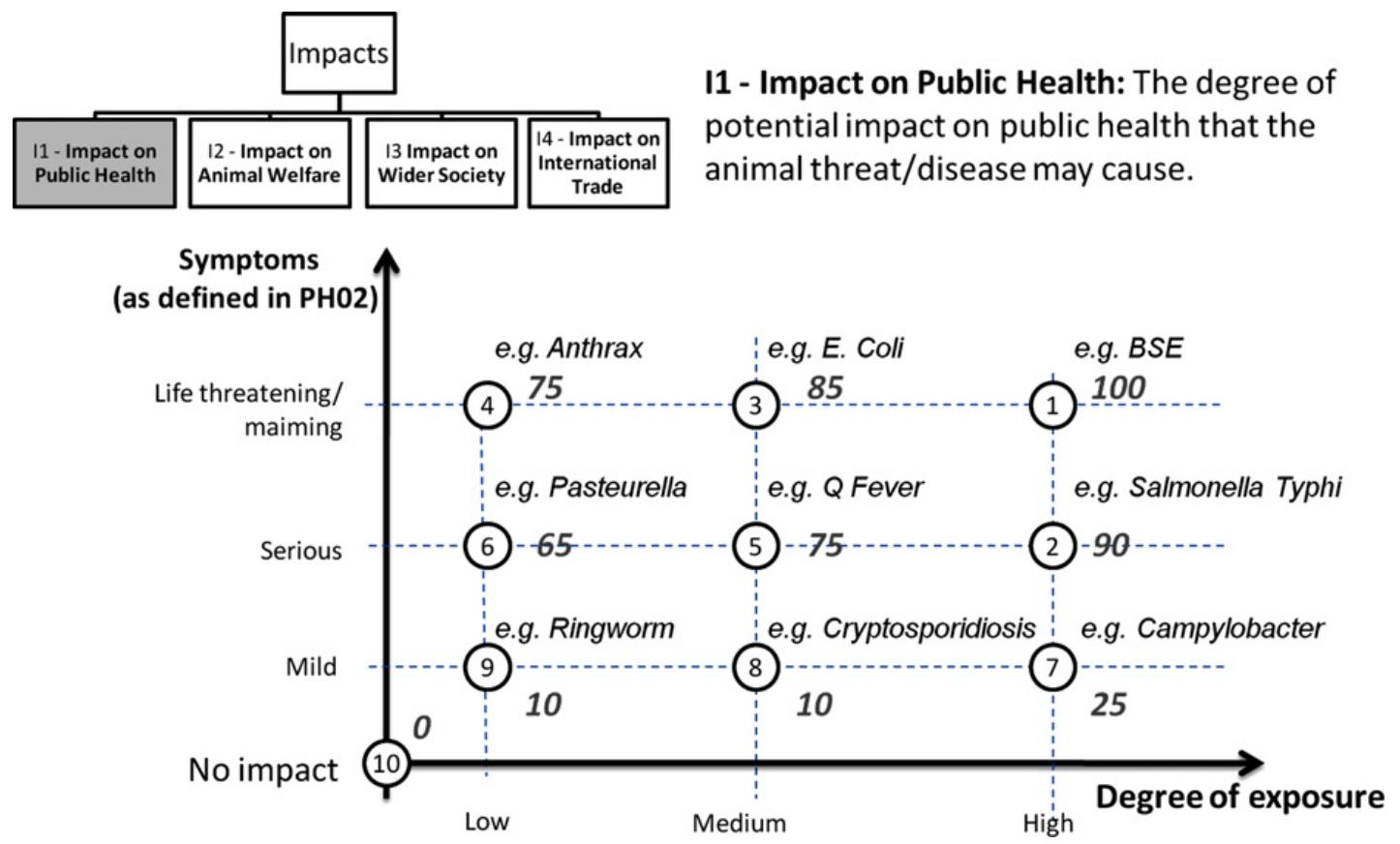
Del Rio, V., Voller, F., Montibeller, G., Franco, L. A., Sribhashyam, S., Watson, E., Hartley, M., \& Gibbens, J. 2013. An integrated process and management tools for ranking multiple emerging threats to animal health.

Preventive Veterinary Medicine, 108(2-3): 94-102. doi:10.1016/j.prevetmed.2012.08.007

Figure 2. Screenshot of the e-THiR Decision Support System (DSS) tool as seen by the Veterinary Risk Group showing three actual threats scored by risk managers. Columns show the criteria used in the DSS: i) impacts on the four reasons for government intervention, ii) capabilities and iii) expert assessment of public perception. The "Compile Data" button, left high corner, compiles the threats from all the risk managers to produce this screenshot. Threats are colour coded so those in red have the greatest impact against a specific criterion. Threats can be sorted within each column, either by the scores against the different criteria or the values of the impact/capability ratio or public perception/impact ratio.

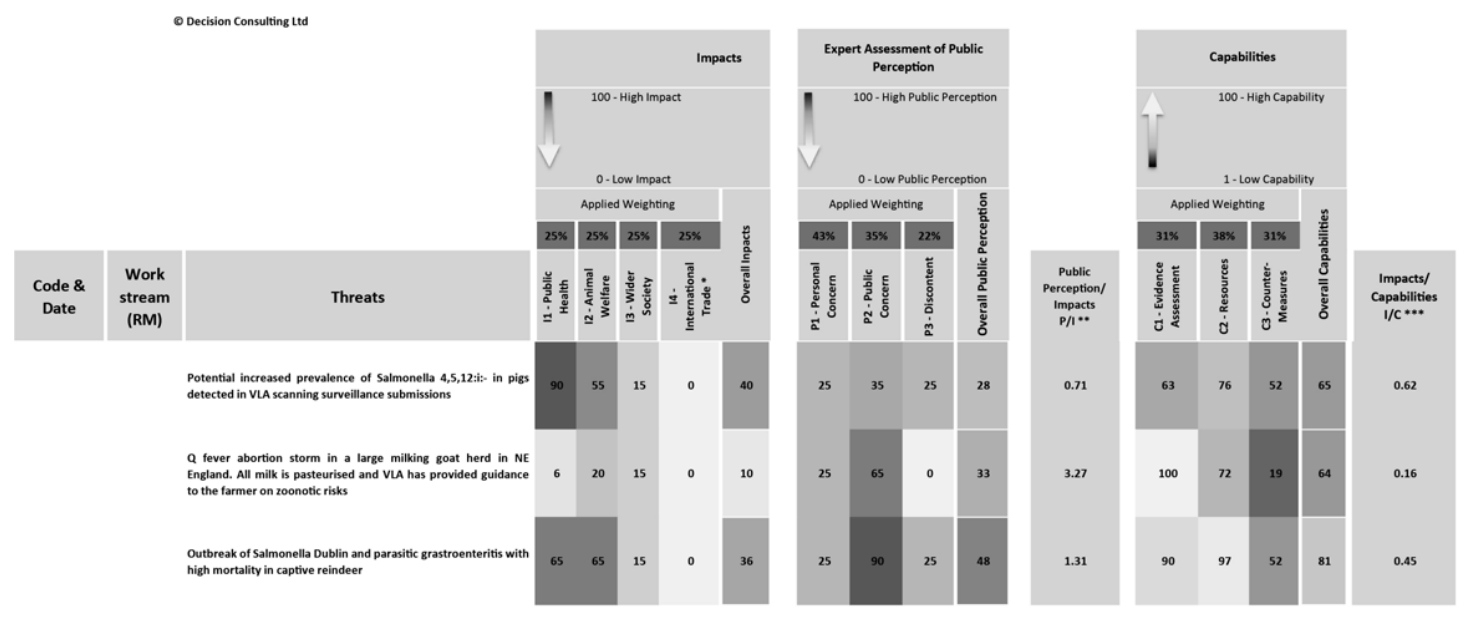

